\title{
The Angelina Jolie Effect in Jewish Law: Prophylactic Mastectomy and Oophorectomy in BRCA Carriers
}

\author{
Sharon Galper Grossman, M.D., M.P.H.* \\ Member of the Medical Advisory Board of The Lemonade Fund, Ra'annana, Israel; Consultant on the \\ Medical Care of Oncology Patients, Ra'annana, Israel
}

\begin{abstract}
Background: Following the announcement of actress Angelina Jolie's prophylactic bilateral mastectomies and subsequent prophylactic oophorectomy, there has been a dramatic increase in interest in BRCA testing and prophylactic surgery.
\end{abstract}

Objective: To review current medical literature on the benefits of prophylactic mastectomy and oophorectomy among BRCA-positive women and its permissibility under Jewish law.

Results: Recent literature suggests that in BRCA-positive women who undergo prophylactic oophorectomy the risk of dying of breast cancer is reduced by $90 \%$, the risk of dying of ovarian cancer is reduced by $95 \%$, and the risk of dying of any cause is reduced by $77 \%$. The risk of breast cancer is further reduced by prophylactic mastectomy. Prophylactic oophorectomy and prophylactic mastectomy pose several challenges within Jewish law that call into question the permissibility of surgery, including mutilation of a healthy organ, termination of fertility, self-wounding, and castration. A growing number of Jewish legal scholars have found grounds to permit prophylactic surgery among BRCA carriers, with some even obligating prophylactic mastectomy and oophorectomy.

Conclusion: Current data suggest a significant reduction in mortality from prophylactic mastectomy and oophorectomy in BRCA carriers. While mutilation of healthy organs is intrinsically forbidden in Jewish law, the ability to preserve human life may contravene and even mandate prophylactic surgery.

KEY WORDS: BRCA, prophylactic surgery, Jewish law

Glossary: G-d, Hebrew manner of writing the name of the Almighty in English; Hashem, G-d; kallah teachers, special instructors of Jewish women on Halachic requirements in marital life; Torah, first five books of Moses; rav, rabbi.

Citation: Galper Grossman S. The Angelina Jolie Effect in Jewish Law: Prophylactic Mastectomy and Oophorectomy in BRCA Carriers. Rambam Maimonides Med J 2015;6 (4):e0037. doi:10.5041/RMMJ.10222

Copyright: (C) 2015 Galper Grossmann. This is an open-access article. All its content, except where otherwise noted, is distributed under the terms of the Creative Commons Attribution License (http://creativecommons.org/licenses/by/3.0), which permits unrestricted use, distribution, and reproduction in any medium, provided the original work is properly cited.

Conflict of interest: No potential conflict of interest relevant to this article was reported.

* E-mail: sharongalper6@yahoo.com 


\section{INTRODUCTION}

In May 2013, the widely acclaimed Hollywood celebrity, Angelina Jolie, published an op-ed in The New York Times announcing that her mother, grandmother, and aunt had had cancer, that she had tested positive for the BRCA mutation, and that she had undergone bilateral prophylactic mastectomies to prevent breast cancer. ${ }^{1}$ This announcement led to what oncologists refer to as "The Angelina Jolie Effect," a more than doubling in the demand for BRCA testing in women who would not otherwise have gone for testing, but were at high risk for carrying the mutation based on family history and therefore should have undergone genetic testing. ${ }^{2}$ In March 2015, Angelina Jolie published a second oped in The New York Times disclosing that she had undergone laparoscopic oophorectomy, removal of the ovaries to prevent ovarian cancer, and that she was receiving hormone replacement therapy to prevent the side-effects of premature menopause. 3

\section{SCIENTIFIC BACKGROUND}

Hereditary breast cancer accounts for $5 \%-10 \%$ of all breast cancer.4-7 The vast majority of inherited breast cancers are due to mutations in two breast cancer genes referred to as BRCA1 and 2. ${ }^{6}$ The risks of developing breast and ovarian cancer are higher in carriers of the BRCA1 mutation compared to carriers of BRCA2. ${ }^{8}$ In addition, cancer is more likely to occur at a younger age in carriers of BRCA1 mutations than in carriers of BRCA2. An average woman has a $12 \%$ lifetime risk of developing breast cancer. 9 In a recent population-based study of Ashkenazi Jews in Israel, regardless of family history, the risks of developing breast cancer among BRCA 1 and 2 carriers were $60 \%$ and $40 \%$, respectively, and the risks of developing ovarian cancer were $53 \%$ and $62 \%$, respectively. ${ }^{10}$ These results are consistent with the findings of a meta-analysis of 10 studies of patients in high-risk clinics which reported that the risks of developing breast cancer by the age of 70 in BRCA1 and 2 carriers are $57 \%$ and $49 \%$, respectively, and the risks of ovarian cancer are $40 \%$ and $18 \%$, respectively. 8 These risks are significantly higher among women born more recently than among women born earlier, a birth cohort effect presumably due to modifications in non-genetic factors such as earlier menarche and later childbearing. ${ }^{10}$

Possible interventions for BRCA carriers might include increased surveillance, chemoprevention, and prophylactic surgery. Surveillance for breast cancer has consisted of MRI and mammogram beginning at age 25 or individualized to 10 years before the first cancer diagnosed in the family. While the addition of MRI to mammogram increases cancer detection rates and diagnoses cancer at an earlier stage, this strategy has not been shown to prolong survival in BRCA carriers. ${ }^{11-14}$ Surveillance for ovarian cancer has consisted of trans-vaginal ultrasound and blood tests for elevated tumor markers such as CA-125. However, this strategy has not been found to be effective. ${ }^{15,16}$ In fact, the National Cancer Institute does not recommend surveillance for ovarian cancer among BRCA carriers.

Another approach to reducing the risk of cancer among BRCA carriers is chemoprevention: tamoxifen to reduce the risk of breast cancer, and oral contraceptive pills to reduce the risks of ovarian cancer. Tamoxifen appears to be effective in reducing breast cancer in carriers of BRCA2 but not in carriers of BRCA1.17,18 The differential effect of tamoxifen may be due to the differential expression of the estrogen receptor in tumors of BRCA carriers. The BRCA1 carriers tend to develop estrogen receptor-negative breast cancers which do not depend on estrogen to grow, and the BRCA2 carriers tend to develop breast cancers that are estrogen receptor-positive and depend on estrogen to grow. ${ }^{19-21}$ Chemoprevention with tamoxifen has not been shown to prolong survival in BRCA2 carriers. ${ }^{17,18}$ Oral contraceptive pills have been shown to reduce the chances of developing ovarian cancer in BRCA carriers by $50 \%$ without increasing the risk of breast cancer, but this intervention has not been shown to reduce the chances of dying of ovarian cancer. ${ }^{22}$

\section{PROPHYLACTIC SURGERY}

Prophylactic surgery consists of mastectomy, removal of the breasts to prevent breast cancer, and oophorectomy, removal of the ovaries to prevent ovarian cancer. Prophylactic mastectomy reduces the chances of developing breast cancer by $90 \%$ or more. ${ }^{23-30}$ In one series, there were no cases of breast cancer 3 years after prophylactic surgery. ${ }^{29}$ Prophylactic oophorectomy reduces the chances of developing ovarian cancer by $80 \%$ and can also reduce the chances of developing breast cancer by $50 \% .{ }^{31-35}$ Carriers of the BRCA mutation may opt for mastectomy alone with surveillance of the ovaries (as Angelina Jolie chose to do between 2013 and 2015), prophylactic oophorectomy alone which will reduce the chances of developing both breast and 
ovarian cancer, or prophylactic mastectomy and oophorectomy (which Angelina Jolie ultimately chose to do). The ideal age to perform prophylactic oophorectomy is not known, but the recommendation is to complete childbearing by age $35-40$ and then undergo prophylactic surgery as there is concern that delaying oophorectomy would increase the chances of developing ovarian cancer. 35 In addition, the magnitude of the protective effects of oophorectomy in reducing the chances of breast cancer is greater the younger the age of oophorectomy. ${ }^{29,36}$ Oophorectomy at this age does cause premature menopause; however, as Angelina Jolie has illustrated, these symptoms can safely be managed with short-term hormone replacement therapy.37-39

How do BRCA carriers cope with prophylactic surgery? Emerging data would suggest that overall quality of life for BRCA carriers who undergo prophylactic surgery is not compromised by surgery. The BRCA carriers who undergo prophylactic surgery report high satisfaction with surgery and less cancer worry than BRCA carriers who opt for surveillance. ${ }^{40,41}$ However, prophylactic surgery may be associated with sexual dysfunction and menopausal symptoms which can be addressed by proper medical intervention. Although it was initially thought, based on theoretical modeling, that BRCA carriers who underwent prophylactic surgery would live longer than those who opted for surveillance, this was not based on actual prospective patient data. ${ }^{2}$ Recently, a number of studies have confirmed that BRCA carriers who undergo prophylactic surgery live longer than those who undergo surveillance. ${ }^{29,35,43}$ In one series, the chances of dying of ovarian cancer were reduced by $95 \%$ among BRCA carriers who opted for prophylactic oophorectomy compared to carriers who opted for surveillance, the chances of dying of breast cancer were reduced by $90 \%$, and the chances of dying of any cause were reduced by 70\%.29 Previously, it was assumed that prophylactic oophorectomy would reduce the chances of a BRCA carrier dying of ovarian cancer but that inducing premature menopause would be harmful and negate any beneficial effects of preventing ovarian cancer. Physicians believed that the BRCA carrier who opted for prophylactic oophorectomy was "trading" ovarian cancer for a host of new medical problems associated with entering premature menopause for no "net" benefit. Yet, the most recent studies show that, overall, BRCA carriers who undergo prophylactic surgery live longer than those who opt for surveillance, demonstrating that, regardless of what medical problems premature menopause may cause, the net effect of prophylactic surgery is that carriers who undergo such surgery live longer. The medical benefits clearly outweigh the risks.

\section{HALACHIC ISSUES}

From a Halachic perspective, there are several concerns arguing against prophylactic surgery (Table 1). First of all, prophylactic surgery involves mutilation of a healthy organ. Secondly, removing a healthy organ-especially one that defines a woman's sexuality and her appearance-may cause significant psychological distress, although the available quality of life data would suggest that from a psychological perspective this surgery is well tolerated. 40,41

Table 1. Halachic Debate over Prophylactic Surgery.

\begin{tabular}{l|l|}
\hline Against & \multicolumn{1}{|c|}{ For } \\
\hline Mutilates healthy organ & Prolongs life \\
Causes psychological distress & \\
Inflicts a wound \\
Destroys ability to be fruitful \\
Violates prohibition against \\
castration
\end{tabular}

In addition, there are two other potential Halachic concerns regarding removal of ovaries. First, removal of ovaries may prevent the BRCA carrier from fulfilling the mitzvah to "be fruitful and multiply" (pru u'revu). Second, removal of ovaries may violate the prohibition against castration (sirus). Arguing in favor of prophylactic surgery are new, emerging, compelling medical data showing that BRCA carriers who undergo prophylactic surgery are less likely to die of cancer and more likely to live longer than women who opt for surveillance. Angelina Jolie's decision prophylactically to remove her healthy breasts and most recently her healthy ovaries raises several Halachic questions including the following: (1) is there a Halachic obligation to prevent disease; (2) is it permitted for a BRCA carrier to remove a healthy organ; (3) does prophylactic surgery violate the prohibition against harming one's body (chovel); (4) does prophylactic oophorectomy prevent the BRCA carrier from ful- 
filling the mitzvah to procreate; (5) does prophylactic oophorectomy violate the prohibition against castration; (6) is it permitted to perform prophylactic surgery in a BRCA carrier; (7) is a BRCA carrier obligated by Halacha to undergo prophylactic surgery; and, lastly, (8) are we as a Jewish society, particularly in Israel, obligated to pay for prophylactic surgery in BRCA carriers?

\section{Is There a Halachic Obligation to Prevent Disease?}

In brief, the Halachic obligation to prevent disease can be based on several texts in the Torah. Rambam in Hilchot Deot cites a verse from Deuteronomy, "Only be careful, and watch yourselves closely," 44 as the basis for the Halachic obligation to prevent disease. 45 Rambam explains that the Halachic basis for preventing disease is to give us the necessary tools to worship Hashem. A healthy body is a necessary condition for performing the commandments (mitzvot) and serving G-d. In addition, Rambam lists a series of medical interventions that we are obligated to adhere to in order to prevent disease, including eating only when hungry, drinking only when thirsty, going to the bathroom when necessary. This is not an exclusive list but a broad list with general applicability and fluidity. Presumably, as medical knowledge evolves, other medical interventions that are determined to prevent disease would fall under the list of interventions that we are obligated to perform to prevent disease and give us the strength to worship Hashem. Although Rav Moshe Feinstein interprets Rambam as a guideline rather than a mandate, ${ }^{46}$ Rabbi Bleich suggests that prophylactic surgery in BRCA carriers which clearly has been shown to prolong survival would fall into the list of medical interventions Halachically required to prevent disease. 47

\section{Is It Permitted for a BRCA Carrier to Remove a Healthy Organ for a Disease That She Does Not Have and May Never Develop?}

Approximately 50\% of BRCA carriers will develop breast cancer, and 50\% ovarian cancer. Is it permitted to remove a healthy breast if $40 \%$ of women undergoing this surgery will never develop breast cancer? Is it permitted to remove healthy ovaries if $50 \%$ of carriers undergoing surgery will never develop ovarian cancer? Rav Feinstein addressed these questions when he was asked whether a woman undergoing hysterectomy could have her healthy ovaries removed at the time of surgery to prevent cancer of the ovaries in the future. It was estimated that the risk of developing ovarian cancer in the woman in question was $5 \% .48$

Rav Feinstein concludes that it is permitted to remove the healthy ovaries of a woman who has a $5 \%$ risk of ovarian cancer in the future and that such surgery is for her benefit (l'tovata). If Rav Feinstein permitted the removal of the healthy ovaries of a woman with a $5 \%$ chance of developing ovarian cancer in the future, then it certainly should be permitted to remove the healthy ovaries of a BRCA carrier with a 50\% chance of developing ovarian cancer in the future and the healthy breasts of a BRCA carrier with a 50\%-60\% chance of developing breast cancer in the future. Such surgery would also be for her benefit.

In this responsa, written in 1982, Rav Moshe expressed concern regarding the risks of complications from surgery and the psychological impact, on the woman in question, of removing healthy organs. Since that time, however, operative techniques have improved and complications have decreased. In fact, Angelina Jolie's surgery was performed laparoscopically with minimal blood loss. In addition, recent data show that BRCA carriers who undergo prophylactic surgery tolerate surgery remarkably well from a psychological perspective.40,41 In light of the dramatic reduction in surgical complications which has occurred in the last 20 years and current data that prophylactic surgery does not cause significant mental distress, it would seem likely that if asked the same question today regarding the permissibility of removing healthy ovaries in a woman who carries a 50\% risk of developing ovarian cancer, Rav Feinstein would be even more inclined to permit such surgery.

\section{Does Prophylactic Surgery Violate the Prohibition against Harming One's Body?}

The prohibition against inflicting a wound or harming one's body (chovel) comes from Leviticus, "Do not cut your bodies for the dead or put tattoo marks on yourselves." 49 When asked if a young girl could undergo cosmetic surgery, Rav Feinstein concluded that such surgery did not violate the prohibition against inflicting a wound since the intention of surgery was not to humiliate the patient but rather to make her more attractive. $5^{\circ}$ In other words, if the purpose of inflicting a wound is not to harm the patient or cause shame or humiliation (biyzayon), 
surgery would be permitted and for the benefit of the woman. Thus, extrapolating from Rav Feinstein's responsa to the case of the BRCA carrier, the prohibition against wounding oneself would not apply to prophylactic surgery as the purpose of such surgery is not to humiliate the carrier, but to prolong her life. Prophylactic surgery would be for the benefit of the carrier (l'tovata). Interestingly, in the conclusion of his responsa, Rav Feinstein quotes the Talmud in Ketubot that states, "Ein Isha eila leyofi," ${ }_{1}$ "a woman is only for beauty" and concludes that if the wound is inflicted to make the woman more beautiful the prohibition against wounding oneself is annulled. If, in fact, wounding oneself is abrogated for surgery that improves a woman's appearance, perhaps Rav Feinstein would conclude that in a BRCA carrier undergoing prophylactic surgery, which deforms the appearance of the woman, the prohibition against wounding oneself persists. However, given that prophylactic surgery prolongs life, ultimately saving a human life (pikuach nefesh) would override the prohibition against inflicting a wound.

\section{Does Prophylactic Oophorectomy}

Prevent the BRCA Carrier From Fulfilling Her Obligation to Procreate (pru u'revu)?

There is much Halachic debate regarding whether a woman has an obligation to procreate, and this is presented in great detail in Tractate Kiddushin. Rav Feinstein addresses this issue in his responsa regarding the woman who is to undergo removal of healthy ovaries at the time of hysterectomy. ${ }^{48} \mathrm{He}$ explains that, even if the woman has an obligation to procreate, the woman in question had completed childbearing and removal of her healthy ovaries could not prevent her from fulfilling the obligation to procreate, assuming such an obligation exists. Similarly, the recommendation for BRCA carriers is to complete childbearing by the age of 35-40 years and then undergo prophylactic oophorectomy. Prophylactic oophorectomy in a BRCA carrier who has completed childbearing would not interfere with a woman's obligation to procreate assuming such an obligation exists for her, as she has already fulfilled her obligation. Similarly, Angelina Jolie had completed childbearing when she underwent prophylactic oophorectomy. Prophylactic oophorectomy in a BRCA carrier who has not completed childbearing by age 40 may interfere with a woman's obligation to procreate if such an obligation exists. However, as women age, they become infertile and, at some point, the BRCA carrier who has not completed childbearing will no longer be able to bear children. Prophylactic oophorectomy in a BRCA carrier who has not borne children but has become infertile would no longer interfere with a woman's obligation to procreate assuming a woman is in fact obligated to procreate, because she is already infertile (akara).

\section{Does Prophylactic Oophorectomy Violate} the Prohibition Against Castration?

The prohibition against castration is derived from Leviticus, "That which is bruised or crushed, torn or cut do not bring before Hashem..." ${ }^{2}$

There is a great deal of debate among Rabbinic scholars regarding the nature of this prohibition. Does it apply just to men or also to women? Is it Rabbinic or Biblical? Does it refer to surgical or medical castration? Rav Feinstein addresses these issues in his responsa regarding removal of healthy ovaries. 48

Even if the prohibition against castration is Biblical and applies to women, he explains that the woman undergoing oophorectomy had already gone through menopause and had already naturally entered a medical/hormonal state of castration. Since the woman had already undergone menopause, removing her ovaries would not violate the prohibition against castration. She had already been autocastrated. It is not possible to castrate a eunuch, because a eunuch is already castrated. Thus, prophylactic oophorectomy in a post-menopausal BRCA carrier would not violate the prohibition against castration, since the ovaries of the BRCA carrier had already ceased to function and she had reached a hormonal state of castration prior to oophorectomy.

However, from a medical perspective, prophylactic oophorectomy in a BRCA carrier should ideally be performed before menopause as the risk of developing ovarian cancer increases with age and the protective effects of prophylactic oophorectomy in reducing the risk of breast cancer are only seen when such surgery is performed before the age of 50.29,36 The younger the BRCA carrier is when prophylactic oophorectomy is performed, the greater the reduction in risk of breast cancer. ${ }^{29,36}$ Hence, does prophylactic oophorectomy in premenopausal BRCA carriers, whose ovaries are still functioning, violate the prohibition against castration? Although the Genius from Vilnius (Vilna Gaon) felt castration in a woman, like a man, is forbidden by the Torah,53 Bach and Rav Shlomo Luria, in Yam 
Shel Shlomo, permit castration in a woman who cannot bear the pains of childbirth and there are no other alternative forms of contraception available.54,55 If the prohibition of castration is overridden by the pains of childbirth, it certainly should be abrogated if surgery would prolong life. A premenopausal BRCA carrier who undergoes prophylactic oophorectomy does not violate the prohibition against castration because the saving of human life ultimately trumps this and any other prohibition. In general, the saving of human life almost always overrides the commandments when the situation is immediately at hand (le'faneinu). The potential saving of human life, which does not exist at the time of decision-making, cannot override prohibitions. Rabbi Avraham Steinberg as well as Rabbi Zalman Nechemiah Goldberg and Rabbi Asher Weiss share this view that for a BRCA carrier the prohibition of castration is annulled by the saving of human life, because the BRCA carrier is in a condition of possible danger to life from conception when she inherited the BRCA mutation.

Thus, the Rabbis cited in this article believe that for a BRCA carrier the risk to human life is imminent and the prohibition against castration, or any other prohibition for that matter, may be annulled to save a human life (personal communication from Rabbi A. Steinberg to the author, May 2015).

\section{Is It Permitted to Perform Prophylactic Surgery in a BRCA Carrier?}

In 2006, Rabbi Moshe Tendler argued that such surgery was not permitted by Halacha. He said: "Although there is a Jewish legal imperative to protect life, it intersects here with the injunction against harming one's own body. No one can fault a woman for running scared and doing these surgeries, but it isn't a 100 percent guarantee" that she will not get these cancers. 56

Rabbi Tendler, at that time, recommended against prophylactic surgery, preferring increased non-invasive surveillance. 57 Given the most recent data showing that prophylactic surgery prolongs life and that surveillance does not (certainly surveillance for ovarian cancer has not been shown to be at all effective), the author contacted Rabbi Tendler to ask if his views have changed. Rabbi Tendler replied that based on the current data "the surgical approach would be the Halachic advisory 8 and prophylactic surgery would be Halachically permitted" (personal communication from Rabbi M.D. Tendler to the author, May 2015). Rav Avraham Steinberg as well as Rav Zalman Nechemiah Goldberg and Rav Asher Weiss also believe that prophylactic surgery is permitted in a BRCA carrier (personal communication from Rabbi A. Steinberg to the author, May 2015).

\section{Is a BRCA Carrier Obligated by Halacha to Undergo Prophylactic Surgery?}

At a 2008 Yeshiva University medical ethics conference titled "Catching Cancer Before It Catches You" Rabbi Mordechai Willig concluded that a BRCA carrier would be obligated to undergo prophylactic surgery. He stated that surgeries should be done, may be "done and maybe from the Halachic perspective MUST be done in order to save lives." 57 Rabbi Yair Hoffman has argued that kallah teachers should be instructing all women to be tested at age 25 and for women who are BRCApositive prophylactic surgery is Halachically recommended at age 35 for BRCA1-positive carriers and after 40 for BRCA2-positive women. $5^{8}$ Rabbi J.D. Bleich has said: "Any medically indicated prophylactic or diagnostic procedure fits with obligation posited by Rambam. Genetic testing, including BRCA should be regarded as Halachically mandated when results are likely to affect treatment and enhance longevity or well-being. One at risk is obligated to pursue all measures to ward off the disease." 47

\section{Are We Obligated as a Jewish Society to Pay for Prophylactic Surgery in BRCA Carriers?}

Rav Eliezer Waldenburg was asked about performing vision testing in children to prevent ophthalmologic disease.59 $\mathrm{He}$ explained that communal funds should be used to finance prophylactic examination based on "Love your neighbor as yourself."6o Extrapolating to the case of BRCA carriers, if BRCA carriers are Halachically obligated to undergo prophylactic surgery, then we as a Jewish society would be obligated to fund both BRCA testing and prophylactic surgery in those who test positive.

\section{CONCLUSION}

In summary, there is a clear Halachic obligation to prevent disease. It is permitted to remove a healthy body part to prevent disease in the future. Prophylactic oophorectomy interferes with obligations to procreate and prohibitions of castration. Oophorectomy after completing childbearing helps eliminate 
issues relating to "procreation." When performed after menopause, prophylactic oophorectomy may obviate the prohibition against castration. Ultimately, saving a life overrides castration and any prohibitions including the prohibition against harming one's body. Given the emerging data favoring prophylactic surgery, a growing number of Jewish arbiters believe that prophylactic surgery is Halachically permitted, with some positing that a BRCA carrier is obligated to undergo prophylactic surgery.

\section{Angelina Jolie's Status in Judaism}

Angelina Jolie's very public medical journey has increased awareness of the BRCA mutation and the demand for testing in high-risk women who would not otherwise have been tested. In addition, she has increased interest in potentially life-saving prophylactic surgery. It is not possible to measure how many lives she has saved by making her very personal, medical odyssey public. Regardless of her other behaviors and politics, her decision to publicize her status as a BRCA carrier and her decisions to undergo prophylactic surgery make her worthy of the description in Sanhedrin, "Whoever saves one Jewish life is considered to have created an entire world." 63

Angelina Jolie has created many worlds, and for this we as a Jewish people must be eternally grateful.

\section{REFERENCES}

1. Pitt AJ. The opinion pages. My medical choice. New York Times, May 14, 2013:A25. Available at: http://www.nytimes.com/2013/05/14/opinion/mymedical-choice.html? $\mathrm{r}=0$. Accessed August 2, 2015.

2. Raphael J, Verma S, Hewitt P, Eisen A. The impact of Angelina Jolie's (AJ) story on genetic referral and testing at an academic cancer centre. J Clin Oncol 2014;32:26(suppl):Abstr 44.

3. Pitt AJ. The opinion pages. Diary of a surgery. New York Times, March 24, 2015:A23. Available at: http://nyti.ms/1OugzvD. Accessed August 2, 2015.

4. Foulkes WD. Inherited susceptibility to common cancers. N Engl J Med 2008;359:2143-53. Full Text

5. Daly MB, Axilbund JE, Buys S, et al. Genetic/familial high-risk assessment: breast and ovarian. J Natl Compr Canc Netw 2010;8:562-94.

6. Narod SA. BRCA mutations in the management of breast cancer: the state of the art. Nat Rev Clin Oncol 2010;7:702-7. Full Text
7. Schorge JO, Modesitt SC, Coleman RL, et al. SGO White Paper on ovarian cancer: etiology, screening and surveillance. Gynecol Oncol 2010;119:7-17. Full Text

8. Chen S, Parmigiani G. Meta-analysis of BRCA1 and BRCA2 penetrance. J Clin Oncol 2007;25:1329-33. Full Text

9. Siegel R, Naishadham D, Jemal A. Cancer statistics, 2012. CA Cancer J Clin Oncol 2012;62:10-29. Full Text

10. King MC, Levy, Lahad E, Lahad A. Population-based screening for breast and ovarian cancer risk due to BRCA1 and BRCA2. Proc Natl Acad Sci 2014;111: 14205-10. Full Text

11. Kriege M, Brekelmans CT, Boetes C, et al. Efficacy of MRI and mammography for breast-cancer screening in women with a familial or genetic predisposition. $\mathrm{N}$ Engl J Med 2004;351:427-37. Full Text

12. Warner E, Hill K, Causer P, et al. Prospective study of breast cancer incidence in women with a BRCA1 or BRCA2 mutation under surveillance with and without magnetic resonance imaging. J Clin Oncol 2011;29: 1664-9. Full Text

13. Grann VR, Jacobson JS, Thomason D, et al. Effect of prevention strategies on survival and quality-adjusted survival of women with BRCA1/2 mutations: an updated decision analysis. J Clin Oncol 2002;20:25209. Full Text

14. Kurian AW, Sigal BM, Plevritis SK. Survival analysis of cancer risk reduction strategies for $\mathrm{BRCA} 1 / 2$ mutation carriers. J Clin Oncol 2010;28:222-31. Full $\underline{\text { Text }}$

15. Hermsen BB, Olivier RI, Verheijen RH, et al. No efficacy of annual gynaecological screening in BRCA1/2 mutation carriers; an observational followup study. Br J Cancer 2007;96:1335-42. Full Text

16. Lacey JV Jr, Greene MH, Buys SS, et al. Ovarian cancer screening in women with a family history of breast or ovarian cancer. Obstet Gynecol 2006;108: 1176-84. Full Text

17. King MC, Wieand S, Hale K, et al. Tamoxifen and breast cancer incidence among women with inherited mutations in BRCA1 and BRCA2: National Surgical Adjuvant Breast and Bowel Project (NSABP-P1) Breast Cancer Prevention Trial. JAMA 2001;286: 2251-6. Full Text

18. Eisen A, Weber BL. Prophylactic mastectomy for women with BRCA1 and BRCA2 mutations--facts and controversy. N Engl J Med 2001;345:207-8. Full Text

19. Narod SA, Brunet JS, Ghadirian P, et al. Tamoxifen and risk of contralateral breast cancer in BRCA1 and 
BRCA2 mutation carriers: a case-control study. Hereditary Breast Cancer Clinical Study Group. Lancet 2000;356:1876-81. Full Text

20. Foulkes WD, Goffin J, Brunet JS, et al. Tamoxifen may be an effective adjuvant treatment for BRCA1related breast cancer irrespective of estrogen receptor status. J Natl Cancer Inst 2002;94:1504-6. Full Text

21. Gronwald J, Tung N, Foulkes WD, et al. Tamoxifen and contralateral breast cancer in BRCA1 and BRCA2 carriers: an update. Int J Cancer 2006;118:2281-4. Full Text

22. Iodice S, Barile M, Rotmensz N, et al. Oral contraceptive use and breast or ovarian cancer risk in BRCA1/2 carriers: a meta-analysis. Eur J Cancer 2010;46:2275-84. Full Text

23. Meijers-Heijboer H, van Geel B, van Putten WL, et al. Breast cancer after prophylactic bilateral mastectomy in women with a BRCA1 or BRCA2 mutation. N Engl J Med 2001;345:159-64. Full Text

24. Rebbeck TR, Friebel T, Lynch HT, et al. Bilateral prophylactic mastectomy reduces breast cancer risk in BRCA1 and BRCA2 mutation carriers: the PROSE Study Group. J Clin Oncol 2004;22:1055-62. Full $\underline{\text { Text }}$

25. Hartmann LC, Schaid DJ, Woods JE, et al. Efficacy of bilateral prophylactic mastectomy in women with a family history of breast cancer. N Engl J Med 1999; 340:77-84. Full Text

26. Hartmann LC, Sellers TA, Schaid DJ, et al. Efficacy of bilateral prophylactic mastectomy in BRCA1 and BRCA2 gene mutation carriers. J Natl Cancer Inst 2001;93:1633-7. Full Text

27. Heemskerk-Gerritsen BA, Brekelmans CT, MenkePluymers MB, et al. Prophylactic mastectomy in BRCA1/2 mutation carriers and women at risk of hereditary breast cancer: long-term experiences at the Rotterdam Family Cancer Clinic. Ann Surg Oncol 2007;14:3335-44. Full Text

28. Geiger AM, Yu O, Herrinton LJ, et al. A populationbased study of bilateral prophylactic mastectomy efficacy in women at elevated risk for breast cancer in community practices. Arch Intern Med 2005;165: 516-20. Full Text

29. Domchek SM, Friebel TM, Singer CF, et al. Association of risk-reducing surgery in BRCA1 or BRCA2 mutation carriers with cancer risk and mortality. JAMA 2010;304:967-75. Full Text

30. Ingham SL, Sperrin M, Baildam A, et al. Riskreducing surgery increases survival in BRCA1/2 mutation carriers unaffected at time of family referral. Breast Cancer Res Treat 2013;142:611. Full Text
31. Rebbeck TR, Lynch HT, Neuhausen SL, et al. Prophylactic oophorectomy in carriers of BRCA1 or BRCA2 mutations. N Engl J Med 2002;346:1616-22. Full Text

32. Kauff ND, Satagopan JM, Robson ME, et al. Riskreducing salpingo-oophorectomy in women with a BRCA1 or BRCA2 mutation. N Engl J Med 2002;346: 1609-15. Full Text

33. NIH consensus conference. Ovarian cancer. Screening, treatment, and follow-up. NIH Consensus Development Panel on Ovarian Cancer. JAMA 1995;273: 491-7. Full Text

34. Haber D. Prophylactic oophorectomy to reduce the risk of ovarian and breast cancer in carriers of BRCA mutations. N Engl J Med 2002;346:1660-62. Full $\underline{\text { Text }}$

35. Finch AP, Lubinski J, Møller P, et al. Impact of oophorectomy on cancer incidence and mortality in women with a BRCA1 or BRCA2 mutation. J Clin Oncol 2014;32:1547-53. Full Text

36. Eisein A, Lubinski J, Klijn J, et al. Breast cancer risk following bilateral oophorectomy in BRCA1 and BRCA2 mutation carriers. J Clin Oncol 2005;23: 7491-6.

37. Eisen A, Lubinski J, Gronwald J, et al. Hormone therapy and the risk of breast cancer in BRCA1 mutation carriers. J Natl Cancer Inst 2008;100:1361-7. Full Text

38. Rebbeck TR, Friebel T, Wagner T, et al. Effect of short-term hormone replacement therapy on breast cancer risk reduction after bilateral prophylactic oophorectomy in BRCA1 and BRCA2 mutation carriers: the PROSE Study Group. J Clin Oncol 2005;23:7804-10. Full Text

39. Domchek SM, Friebel T, Neuhausen SL, et al. Is hormone replacement therapy (HRT) following riskreducing salpingo-oophorectomy (RRSO) in BRCA1 and BRCA2 mutation carriers associated with an increased risk of breast cancer? J Clin Oncol 2011; 29(Suppl):1501.

40. Madalinsk JB, Hollenstein J, Bleiker E, et al. Qualityof-life effects of prophylactic salpingo-oophorectomy versus gynecologic screening among women at increased risk of hereditary ovarian cancer. J Clin Oncol 2005;23:6890-8. Full Text

41. Van Oostrom I, Meijers-Heijboer H, Lodder LN, et al. Long-term psychological impact of carrying a BRCA1/2 mutation and prophylactic surgery: a 5-year follow-up study. J Clin Oncol 2003;21:3867-74. Full Text

42. Schrag D, Kuntz KM, Garber JE, Weeks JC. Decision analysis-effects of prophylactic mastectomy and 
oophorectomy on life expectancy among women with BRCA1 or BRCA2 mutations. N Engl J Med 1997;336: 1465-71. Full Text

43. Domchek SM, Friebel TM, Neuhausen SL, et al. Mortality after bilateral salpingo-oophorectomy in BRCA1 and BRCA2 mutation carriers: a prospective cohort study. Lancet Oncol 2006;7:223-9. Full Text

44. Deuteronomy 4:9.

45. Maimonides (1138-1204). Deot 4:2.

46. Iggerot Moshe, Choshen Mishpat II, 76.

47. Bleich JD. Genetic screening: survey of recent Halakhic periodical literature. Tradition 2000;34: 63-87.

48. Rabbi Feinstein M (1895-1986). Responsa Iggerot Moshe, Choshen Mishpat, Part 2, \#73.

49. Leviticus 19:28.

50. Rabbi Feinstein M (1895-1986). Responsa Iggerot Moshe, Choshen Mishpat, Part 2, \#66.

51. Babylonian Talmud, Tractate Ketubot 52b.

52. Leviticus 22:24.
53. Rabbi Elijah ben Shlomo Zalman (The Genius from Vilnius, 1720-1797). Even HaEzer siman 5:25.

54. Rabbi Joel ben Samuel Sirkis (Bayit Chadash, Bach, 1561-1640). Even HaEzer. 5, s.v. ve’isha.

55. Rabbi Luria S (Maharshal, 1510-1573). Yam Shel Shlomo, Y'vamot 6:44.

56. Cohen DN. Fighting the odds. New York Jewish Week, July 28, 2006:13:32.

57. Willig MI. Catching cancer before it catches you: Medical and Halachic implications of BRCA gene testing (Audio Lecture). Yeshiva University Medical Ethics Forum. 2008. The Macros and Adina Katz YUTorah Online. Accessed September 1, 2015.

58. Rabbi Hoffman Y. Kallah teachers, BRCA testing, and surgery. 5 Towns Jewish Times, May 4, 2014.

59. Rabbi Waldenberg EY (1915-2006). Responsa Tzitz Eliezer, 15:40.

60. Leviticus 19:18.

61. Babylonian Talmud, Tractate Sanhedrin 37a. 